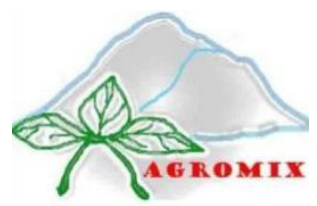

\title{
AGROMIX
}

Jurnal IImiah Fakultas Pertanian, Universitas Yudharta Pasuruan pISSN (Print): 2085-241X; elSSN (Online): 2599-3003

Website: https://jurnal.yudharta.ac.id/v2/index.php/agromix

\section{Pengaruh switching value terhadap finansial usaha kerupuk ikan cumi (Loligo sp.) di Desa Weru Kecamatan Paciran Kabupaten Lamongan}

\author{
The effect of switching value on financial business fish crop (Loligo sp.) In Weru Village, Paciran District, Lamongan \\ Regency
}

Dona Wahyuning Laily ${ }^{1^{*}}$, Ika Purnamasari ${ }^{1}$

${ }^{1}$ Program Studi Agrobisnis Perikanan, Fakultas Perikanan, Univeristas Islam Lamongan, Jawa Timur

*Email Korespodensi: donalaily29@gmail.com

\begin{abstract}
\section{Article History}

Received : July 29, 2021

Accepted : September 10, 2021

Published : September 28,2021

Keyword

Financial Business; Switching

Analysis; Fish Crop

Lamongan Regency is known as the largest fishery area in East Java. This will give benefit the fishing community in terms of fishermen's welfare. Most of the fish caught are sold directly to middlemen (tengkulak) and only a few fishermen did the increasing value in the form of processed fish or diversification of products. The purpose of this study was to analyze the finances in Weru Village, Paciran District, Lamongan Regency. This research was conducted from July to October 2020, using primary data with a syrvey method for the business of squid chips processing in Weru Village, Paciran District, Lamongan Regency. The financial feasibility of squid chips processing business is analyzed by using several investment criteria, namely Net Present Value, Internal Rate of Return, Payback Period, Net B/C Ratio. Business sensitivity is analyzed by using switching value. Based on the results of reserach, the business of manufacturing squid chips is feasible. The financial value that can be obtained is the NPV value of Rp. $80,835,098.13$, IRR of 61,87 percent, net $B / C$ of 1.81 and payback period of 3 years and 25 days. Meanwhile, the sensitivity analysis shows that the decrease in selling proce is more sensitive than the decrease in the proce of raw materials. The highest increase in the price of raw materials was 39.92 percent and the percentage of decrease in the selling proce of squid chips with the lowest value was 21,87 percent.
\end{abstract}

\section{Riwayat Artikel}

Dikirim : 29 Juli, 2021

Disetujui : 10 September, 2021

Dipublis : 28 September 2021

\section{Kata Kunci}

Kelayakan Finansial; Switching analisis; Kerupuk Cumi

\section{ABSTRAK}

Kabupaten Lamongan dikenal sebagai daerah penghasil perikanan tangkap terbesar di Jawa Timur. Hal ini akan memberi manfaatberdampak pada masyarakat nelayan dalam segi kesejahteraan masyarakat pesisir. Umumnya hasil tangkapan ikan sebagian besar dijual langsung kepada tengkulak (pedagang ikan) dan hanya sedikit saja yang melakukan peningkatan nilai tambah dalam bentuk olahan ikan atau diversifikasi produk. Tujuan dari penelitian ini adalah menganalisis kelayakan finansial dan sensitivitas usaha pada usaha pengolahan kerupuk cumi di Desa Weru Kecamatan Paciran kabupaten Lamongan. Penelitian ini dilakukan pada Bulan Juli sampe Oktober 2020, menggunakan data primer dengan metode survey untuk usaha pengolahan kerupuk cumi di Desa Weru Kecamatan Paciuran Kabupaten Lamongan. Kelayakan finansial usaha pengolahan kerupuk cumi ini di analisis menggunakan beberapa kriteria investasi yaitu Net Present Value, Internal Rate of Return, Payback Period, Net B/C Ratio. Sensitifitas usaha di analisis dengan menggunakan switching value. Berdasarkan hasil penelitian, usaha pengolahan kerupuk cumi layak untuk di usahakan. NUntuk nilai finansial yang di dapat adalah nilai NPV sebesar Rp. 80.835.098,13, IRR sebesar 61,87 persen, Net B/C sebesar 1,81 dan payback period sebesar 3 tahun 25 hari. Sedangkan, Untuk analisis sensitifitas menunjukkan penurunan harga jual yang lebih sensitif daripadaapabila dibandingkan dengan penurunan harga bahan baku. Kenaikan harga bahan baku tertinggi adalah sebesar 39,92 persen dan persentase tingkat penurunan harga jual kerupuk cumi dengan nilai terendah sebesar 21,87 persen.

\footnotetext{
Sitasi: Laily, D. W., \& Purnamasari, I. (2021). Pengaruh switching value terhadap finansial usaha kerupuk ikan cumi (Loligo sp.) di Desa Weru Kecamatan Paciran Kabupaten Lamongan. Agromix, 12(2), 6-11. https://doi.org/10.35891/agx.v12i2.2604
}

\section{PENDAHULUAN}

Indonesia merupakan negara Kepulauan yang terdiri dari sekitar 17.504 pulau dengan panjang garis pantai kurang lebih $81.000 \mathrm{~km}$. Di sepanjang garis pantai ini terdapat wilayah pesisir yang relatif sempit tetapi memiliki potensi sumber daya alam hayati dan non-hayati; sumber daya buatan; serta jasa lingkungan yang sangat penting bagi kehidupan masyarakat. Sebagai negara Kepulauan terbesar di dunia, Indonesia memiliki potensi laut yang sangat 
besar. Menurut Hutajulu dkk. (2019), Indonesia merupakan negara yang memiliki sumber daya perikanan dengan keanekaragaman spesies tertinggi di dunia. Pengkajian stok ikan di perairan Indonesia menunjukkan bahwa potensi lestari sumber daya perikanan Indonesia mencapai 6.4 juta ton/tahun. Sebagian besar adalah ikan, namun cumi merupakan salah satu potensi laut yang menarik untuk dikembangkan.

Ikan olahan tradisional (traditional cured) merupakan produk yang diolah secara sederhana dan umumnya dilakukan untuk skala industri rumah tangga karena alat dan cara pengolahan dilakukan dengan cara yang sederhana dan tidak membutuhkan modal yang besar. Untuk pengolahan kerupuk cumi adalah salah satu cara pengolahan tradisional yang berperan dalam memanfaatkan hasil-hasil perikanan yang banyak dimanfaatkan oleh nelayan dengan skala usaha yang kecil (Searles dkk., 2018).

Saat ini pengolahan produk hasil tangkap perikanan dapat menciptakan nilai tambah yang nantinya akan meningkatkan pendapatan dalam rumah tangga. Menurut Hutajulu dkk. (2019) bahwa melakukan analisis nilai nilai tambah dapat mengetahui besarnya imbalan yang diterima oleh pengusaha maupun tenaga kerja. Analisis usaha ini juga berguna dalam mengetahui seberapa besar tambahan nilai yang terdapat pada satuan output yang dihasilkan. Menurut Jumiati \& Sudianto (2019) bahwa investasi pribadi memiliki efek yang signifikan dan positif terhadap produksi nilai tambah, penyerapan tenaga kerja dan produktivitas tenaga kerja.

Kabupaten Lamongan adalah salah satu kabupaten di Provinsi Jawa Timur dengan luas wilayah sekitar $1.812,80$ $\mathrm{km}^{2}$ setara 181.280 ha atau kurang lebih 3.78 persen dari luas wilayah Provinsi Jawa Timur dengan panjang garis pantai sepanjang $47 \mathrm{~km}$. Secara geografis, Kabupaten Lamongan terletak pada $6^{0} 51^{\prime}-7^{0} 23^{\prime}$ Lintang Selatan dan $112^{0} 33^{\prime}-112^{0} 34^{\prime}$ Bujur Timur. Batas wilayah administratif Kabupaten Lamongan adalah: sebelah utara : Laut Jawa, sebelah timur : Kabupaten Gresik, sebelah selatan : Kabupaten Jombang dan Kabupaten Mojokerto, sebelah barat : Kabupaten Bojonegoro dan Kabupaten Tuban.

Potensi perikanan yang dimiliki oleh Kabupaten Lamongan cukup besar, menurut BPS (2018) produksi perikanan Lamongan tahun 2017 mencapai 126.565, 46 dengan produksi perikanan tangkap sebesar 74.196,30 ton dan perikanan budidaya sebesar 52.369,16 ton. Produksi perikanan tangkap di Lamongan merupakan jumlah terbesar di Jawa Timur. Namun rata-rata nelayan di Kabupaten Lamongan belum bisa dikatakan sejahtera. Hal ini dipengaruhi oleh beberapa faktor, salah satunya adalah dominasi sistem jual beli nelayan dan dikenal dengan sistem "patronklien". Hal ini diartikan bahwa tengkulak menguasai harga beli ikan karena ada ikatan hutang pada nelayan. Dengan adanya hal ini maka perlu dilakukan peningkatan pendapatan dalam rumah tangga dengan cara diversifikasi usaha mengenai pengolahan ikan secara tradisional seperti membuat kerupuk ikan, terasi ikan, abon ikan, ikan asap, pindang dan lain-lain (Principal dkk., 2019).

Sebagai wilayah pesisir, Kabupaten Lamongan mempunyai potensi yang besar dalam percumian, baik percumian air tawar, air payau, maupun air laut. Kita tinggal di negara yang mempunyai bentangan luas dengan segala kekayaan alam yang ada di dalamnya. Khususnya cumi - cumi, meskipun tingkat konsumsi cumi masyarakat Indonesia masih rendah di bandingkan daerah lain tapi grafiknya terus meningkat dari tahun-ketahun. Salah satu produk percumian yang sering di jumpai oleh masyarakat adalah Kerupuk. Kerupuk cumi - cumi ini merupakan suatu komoditas percumian yang memiliki rasa cukup enak dan gurih sehingga banyak digemari masyarakat. Karena di sebagian besar masyarakat berpendapat bahwa kerupuk merupakan pendamping makanan serta sajian kuliner nusantara. Kerupuk merupakan makan dengan harga yang terjangkau oleh segala lapisan masyarakat (Intyas \& Firdaus, 2020).

Besarnya potensi dalam produksi cumi yang dimiliki oleh Kabupaten Lamongan, akan banyak menciptakan lapangan pekerjaan khususnya industri kecil dan kerajinan rumah tangga yang merupakan salah satu sektor pengolahan dan mempunyai andil sangat besar dalam menciptakan lapangan pekerjaan. Pengolahan kerupuk cumi di Desa weru Kecamatan Paciran Kabupaten Lamongan akan dapat memaksimalkan manfaat hasil tangkapan, meningkatkan nilai tambah ekonomi dan memperpanjang daya tahan simpanan sehingga hasil produksi akan berpengaruh terhadap sosial ekonomi nelayan tersebut. Untuk mempertahankan kualitas bahan pangan (cumi), salah satunya adalah kegiatan pengolahan (Irianto \& Giyatmi, 2009)

Namun demikian, adanya dampak negatif dari pengolahan kerupuk cumi ini adalah banyaknya sentra pengolahan kerupuk cumi yang akan berdampak terhadap persaingan harga produk di pasaran dan ditambah lagi usaha pengolahan kerupuk ikan cumi merupakan usaha yang turun-temurun atau warisan keluarga serta analisis sensitivitas merupakan analisis yang dilakukan untuk mengetahui akibat dari perubahan parameter-parameter produksi terhadap perubahan kinerja sistem produksi dalam menghasilkan keuntungan. Dengan melakukan analisis sensitivitas ini maka akibat yang mungkin terjadi dari perubahan tersebut dapat diketahui dan dapat diantisipasi oleh pengusaha kerupuk cumi tersebut. Menurut Hopkins (2016) menyatakan bahwa suatu variasi pada analisis sensitivitas adalah nilai pengganti (switching value), switching value adalah perhitungan untuk mengukur perubahan maksimum. Perubahan yang mendasar antara analisis sensitivitas yang biasa dilakukan dengan switching value adalah pada analisis sensitivitas yang besarnya perubahan sudah diketahui secara empirik. Penelitian ini bertujuan untuk menganalisis biaya, penerimaan, keuntungan dan tingkat sensitivitas usaha pengolahan kerupuk cumi di Desa Weru Kecamatan Paciran Kabupaten Lamongan. 


\section{METODE}

Jenis penelitian yang digunakan pada penelitian ini adalah penelitian studi kasus dengan metode purposive sampling. Data yang digunakan dalam penelitian ini adalah data primer dan data sekunder. Data primer diperoleh dari harga jual, harga input, komponen biaya investasi, biaya operasional, dan biaya tetap. Data sekunder yang dikumpulkan dalam penelitian bersumber dari laporan keuangan rumah tangga.

Untuk pengolahan data yaitu menggunakan data kualitatif dan kuantitatif. Data kualitatif dilakukan untuk mengetahui karakteristik usaha kerupuk ikan cumi tersebut yang disajikan pada aspek-aspek non finansial dalam bentuk uraian deskriptif, tabel, bagan atau gambar untuk mempermudah pemahaman. Sedangkan data kuantitif disajikan untuk mengetahui keadaan usaha tersebut secara finansial seperti Net Present Value (NPV), Internal Rate Return(IRR), Net B/C Ratio, Payback Period (PP), Break Event Point (BEP), Retirn On Investment (RPO), serta Analisis Sensitivitas (Hopkins, 2016).

\section{Net Present Value (NPV)}

Menurut (Hopkins, 2016) NPV adalah nilai neto sekarang dari dana yang diinvestasikan selama umur proyek. NPV mencerminkan besarnya tingkat pengembalian dari usulan usaha atau penelitian, oleh karena itu usulan penelitian atau usaha yang layak diterima haruslah memiliki nilai NPV $>0$, jika tidak maka proyek itu akan merugi. Rumus yang digunakan dalam NPV adalah sebagai berikut:

$$
N P V=\sum_{t=1}^{n} \frac{C F}{[1-r]}-I o
$$

Dimana:

$$
\begin{array}{ll}
\text { NPV } & =\text { Net present value atau Nilai sekarang } \\
\Sigma & =\text { Simbol untuk penjumlahan } \\
\mathrm{t} & =\text { Periode waktu atau tahun ke } \mathrm{t}
\end{array}
$$

\section{Net $B / C$ ratio}

Merupakan perbandingan antara NPV total dari benefit bersih terhadap total dari biaya bersih. B/C menunjukkan manfaat bersih yang diperoleh setiap penambahan satu rupiah pengeluaran bersih. Perhitungan dengan menggunakan rumus (Gitinjer, 1986).

Penilaian kelayakan finansial berdasarkan Net B/C Ratio, yaitu:

$$
\text { Net B.C }=\frac{\sum_{t-1}^{n} \frac{B t-C t}{(1+i)}}{\sum_{t-1}^{n} \frac{C t-B t}{(1+i)}}
$$

$\checkmark \quad$ Net B/C Ratio >1, maka proyek layak atau dapat dilaksanakan

$\checkmark \quad$ Net $B / C$ Ratio $=1$, maka proyek impas antara biaya dan manfaat sehingga ter6serah kepada pengambilan keputusan untuk dilaksanakan atau tidak.

$\checkmark \quad$ Net B/C Ratio < 1, maka tidak layak atau tidak dapat dilaksanakan.

\section{Break event point (BEP)}

Merupakan suatu alat analisis yang digunakan untuk mengetahui hubungan antar beberapa variabel di dalam usaha yang $d$ rintis oleh perusahaan seperti, luas produksi atau tingkat produksi yang dilaksanakan, biaya yang dikeluarkan, serta pendapatan yang diterima perusahaan dari kegiatannya. Keadaan pulang pokok merupakan keadaan dimana penerimaan pendapatan (total revenue) yang disingkat TR adalah biaya yang ditanggungnya (total cost) yang disingkat TC.

Penentuan break even didasarkan pada persamaan penjualan dengan total biaya. Adapun perhitungan BEP menurut Nazir (2005) adalah sebagai berikut:

$$
\begin{array}{r}
\text { BEP harga jual }=\frac{\text { Total Biaya Produksi }}{\text { Total Produksi }} \\
\text { BEP untuk volume produksi }=\frac{\text { Total Biaya Produksi }}{\text { Harga Jual Produksi }}
\end{array}
$$

\section{Payback period}

Payback Period (PP) merupakan jangka waktu yang diperlukan untuk membayar kembali pengeluaran investasi suatu usaha. Semakin cepat kemampuan suatu usaha mengembalikan biaya-biaya yang telah dikeluarkan dalam investasi usaha maka usaha tersebut semakin layak. Rumus yang digunakan adalah: 
Keterangan:

$$
P P=\frac{I}{A b}
$$

I = Besarnya biaya investasi yang diperlukan

$\mathrm{Ab} \quad=$ Manfaat bersih yang dapat diperoleh pada setiap tahunnya.

\section{Switching value (Analisis Sensitifitas)}

Analisis sensitivitas perlu dilakukan karena dalam analisis kelayakan usaha, perhitungan umunya didasarkan pada proyeksi-proyeksi yang mengandung ketidakpastian tentang apa yang akan terjadi di waktu yang akan datang. Tujuan analisis sensitivitas adalah untuk menilai apa yang terjadi dengan hasil analisis kelayakan suatu kegiatan investasi atau bisnis apabila terjadi perubahan di dalam perhitungan biaya atau manfaat.

Menurut Gitinjer (1986) bahwa switching value merupakan kegiatan analisis yang mencoba melihat seberapa besar perubahan maksimum yang dapat mempengaruhi kelayakan suatu usaha. Analisis sensitivitas pada pengolahan kerupuk cumi ini menggunakan metode nilai pengganti (switching value) dengan mengganti nilai komponen tersebut sangat mempengaruhi keadaan finansial suatu usahatani. Analisis sensitivitas dalam penelitian ini menggunakan parameter kenaikan harga bahan baku dan penurunan harga bahan baku. Analisis ini dilakukan pendekatan dengan dua parameter: Parameter 1, Apabila terjadi kenaikan harga bahan baku ikan cumi 5 persen, 10 persen dan 15 persen, parameter 2, dan Parameter 2, jika terjadi penurunan harga jual kerupuk ikan cumi 5 persen, 10 persen dan 15 persen.

\section{HASIL DAN PEMBAHASAN}

Rumah tangga nelayan kecil di Desa Weru, Kecamatan Paciran Kabupaten Lamongan ini melakukan beberapa alternatif dalam melakukan mata pencaharian untuk memenuhi kebutuhan hidup keluarganya. Hal ini dikarenakan hasil tangkapan ikan yang semakin tidak menentu dan kondisi musim yang tidak bisa diprediksi.

Masyarakat nelayan di Desa weru ini mempunyai ide untuk mengolah secara tradisional dan menjadi salah satu pilihan bagi rumah tangga nelayan skala kecil karena jumlah hasil tangkapan per nelayan relatif sedikit, jenis dan ukuran ikan yang beragam serta tidak memerlukan modal yang besar. Salah satunya adalah dengan melakukan pengolahan menjadi kerupuk ikan cumi yang dilakukan oleh koperasi desa yang ada di Desa Weru Kecamatan Paciran Kabupaten Lamongan.

Pengolahan secara sederhana terhadap hasil tangkapan ikan khususnya cumi dapat menciptakan nilai tambah (value added) yang diharapkan dapat meningkatkan pendapatan bagi rumah tangga nelayan yaitu usaha pengolahan kerupuk ikan cumi. Menurut Tama dkk. (2019) kerupuk pada umumnya dibuat dari tepung tapioka sebagai sumber pati dengan penambahan bumbu dan air serta memiliki kandungan gizi yang rendah. Penambahan gizi kerupuk dapat dilakukan dengan menambahkan daging ikan. Sementara di sisi lain, jenis ikan sebagai bahan baku utama pada pembuatan kerupuk ikan sangat berpengaruh terhadap warna, tekstur dan rasa kerupuk ikan sendiri.

\section{Analisis kelayakan finansial}

Analisis kelayakan merupakan salah satu cara untuk menilai investasi yang digunakan layak atau tidak dan berdasarkan penelitian yang telah kami lakukan, maka hasil perhitungan analisis kelayakan finansial Usaha Pengolahan Kerupuk Cumi dilihat dari kriteria kelayakan usaha dapat dilihat pada tabel berikut:

Tabel 1. Kriteria kelayakan finansial usaha pengolahan kerupuk cumi di Desa Weru Kecamatan Paciran Kabupaten Lamongan

\begin{tabular}{llc}
\hline No. & \multicolumn{1}{c}{ Kriteria Kelayakan } & Nilai \\
\hline 1 & Net Present Value (NPV) (Rp) & Rp. 80.835.098,13 \\
2 & Internal Rate Return(IRR) (\%) & $61,87 \%$ \\
3 & Net benefit cost ratio (Net B/C) & 1,81 \\
4 & Payback period & 3 tahun 25 hari \\
\hline
\end{tabular}

Sumber: Data primer (di olah), 2020

Penghitungan didasarkan pada nilai rata-rata pendapatan yang diperoleh oleh 5 pengrajin kerupuk cumi yang ada di di Desa Weru Kecamatan Paciran Kabupaten Lamongan, dan seperti yang sudah di uraikan sebelumnya, hasil perhitungan dengan kriteria investasi merupakan salah satu cara untuk menilai apakah usaha yang dijalankan layak atau tidak dan berdasarkan hasil yang di peroleh dari 4 kriteria investasi, yang pertama nilai Net Present Value (NPV) yang diperoleh dari usaha pengolahan kerupuk cumi adalah sebesar Rp 80.835.098,13, hal ini berarti bahwa usaha pengolahan kerupuk cumi layak untuk dilanjutkan, karena laba dimasa depan lebih tinggi dari pada biaya yang digunakan pada masa sekarang (Amelia dkk., 2020).

Untuk melihat Internal Rate of Return (IRR) menggunakan tingkat suku bunga untuk menyamakan nilai investasi dengan nilai saat ini. Nilai Internal Rate of Return (IRR) dari usaha kerupuk ikan cumi di Desa Weru Kecamatan Paciran Kabupaten lamongan adalah sebesar 61,87 persen, hal ini berarti bahwa nilai usaha pengolahan kerupuk cumi di Desa 
Weru Kecamatan Paciran Kabupaten Lamongan layak untuk di usahakan. Hal ini sesuai dengan pernyataan dari Shava \& Gunhidzirai (2017), investasi akan dianggap layak apabila memiliki IRR lebih besar daripada tingkat suku bunga yang berlaku saat ini dan suatu investasi dianggap tidak layak apabila memiliki nilai IRR yang lebih kecil dari tingkat suku bunga yang berlaku.

Net benefit cost ratio (Net B/C), merupakan kriteria ketiga yang digunakan dalam penelitian ini, untuk menilai layak tidaknya usaha yang dijalankan dimana jika nilai Net B/C lebih dari 1, yang berarti setiap satu rupiah yang dikeluarkan akan mendapat atau menghasilkan manfaat bersih melebihi tambahan biaya yang dikeluarkan, dan berdasarkan penelitian yang telah dilakukan maka nilai Net B/C yang diperoleh sebesar 2,75 yang berarti lebih besar dari 1 dan mengindikasikan usaha pengolahan kerupuk cumi yang di lakukan layak untuk dikerjakan.

Pada usaha pengolahan kerupuk ikan cumi ini payback period yang diperoleh 3 tahun 25 hari, dan ini merupakan waktu yang cukup lama untuk pengembalian modal usaha, karena semakin cepat pengembalian biaya investasi, maka akan makin cepat juga perputaran modal untuk keberlangsungan usaha yang dijalankan. hal yang sama dikatakan oleh Winarti dkk. (2018) bahwa Payback Period adalah jangka waktu yang digunakan untuk menilai pengembalian modal dalam suatu usaha, atau untuk mengetahui berapa lama usaha yang dijalankan baru dapat mengembalikan investasi

Berdasarkan hasil yang sudah d kemukakan di atas, maka usaha pengolahan kerupuk ikan cumi di Desa Weru Kecamatan Paciran Kebupaten Lamongan layak untuk dilanjutkan. Dari segi manfaat, usaha pengolahan ikan cumi ini memberikan keuntungan yang tinggi bagi pengusaha kerupuk ikan cumi di Desa Weru Kabupaten Lamongan, sehingga usaha yang mereka jalankan akan mampu bertahan.

\section{Analisis switching value (Analisis Sensitifitas)}

Hasil analisis switching value dengan menggunakan parameter 1 yaitu terjadi kenaikan harga bahan baku pengolahan kerupuk cumi sebesar 5 persen, 10 persen dan 15 persen dapat dilihat tabel di bawah ini:

Tabel 2. Parameter 1 terjadi kenaikan harga bahan baku naik 5 persen, 10 persen dan 15 persen

\begin{tabular}{llccc}
\hline No . & Kriteria kelayakan & 5 persen & 10 persen & 15 persen \\
\hline 1. & Net Present Value (Rp) & $74.780 .176,98$ & $69.900 .764,90$ & $56.530 .115,67$ \\
2. & Internal rate of return (IRR) & 53,90 persen & 46,29 persen & 39,92 persen \\
3. & Net benefit cost ratio (Net B/C) & 2,52 & 2,27 & 2,08 \\
4. & Payback period (Bulan) & 3 tahun 7 & 3 tahun 12 & 4 tahun 4 bulan, \\
& & bulan 8 hari & bulan 18 hari & 12 hari \\
\hline
\end{tabular}

Sumber: Data primer(diolah), 2020

Berdasarkan hasil pada Tabel 2 mengindikasikan bahwa pengolahan kerupuk cumi layak untuk diusahakan walau terjadi kenaikan bahan baku sampai 15 persen. Namun di sisi lain untuk pengembalian modal atau payback period kenaikan bahan baku memberikan pengaruh pada jangka waktu yang lebih lama, sehingga akan memperlambat masa pengembalian modal yang digunakan sebagai investasi awal usaha.

Tabel 3. Parameter 2 terjadi penurunan harga jual kerupuk 5 persen, 10 persen dan 15 persen

\begin{tabular}{llccc}
\hline No . & Kriteria Kelayakan & 5 persen & 10 persen & 15 persen \\
\hline 1. & Net Present Value (Rp) & $59.934 .548,76$ & $41.659 .315,45$ & $31.450 .165,38$ \\
2. & Internal rate of return (IRR) & 46,09 persen & 33,87 persen & 21,87 persen \\
3. & Net benefit cost ratio (Net B/C) & 2,35 & 1,98 & 1,87 \\
4. & Payback period (Bulan) & 3 tahun 10 & 4 tahun 9 bulan & 5 tahun 6 bulan, 3 \\
& & bulan 6 hari & 12 hari & hari \\
\hline
\end{tabular}

Sumber: Data primer(diolah), 2020

Penurunan harga jual pada parameter kedua menandakan bahwa penurunan harga jual lebih sensitif dibandingkan dengan kenaikan bahan baku. Hal ini sesuai dengan penelitian Winarti L. 2016 dimana penurunan harga jual lebih sensitif dibandingkan dengan penurunan harga bahan baku dalam pengolahan kerupuk cumi, dah hal ini terlihat pada sensitifitas 15 persen untuk payback period dan mempunyai jangka waktu lebih lama yaitu 5 tahun 6 bulan 4 hari. Hasil analisis switching value mempunyai batas maksimum kenaikan harga bahan baku adalah 39,92 persen dan batas penurunan harga jual kerupuk cumi sebesar 21,87 persen.

Tabel 4. Analisis switching value

\begin{tabular}{clc}
\hline No. & Parameter & Nilai (\%) \\
\hline 1. & Kenaikan harga bahan baku tertinggi & 39,92 \\
2. & Penurunan harga jual & 21,87 \\
\hline
\end{tabular}

Sumber: Data primer(diolah), 2020

Hasil analisis switching value dapat dilihat bahwa batas maksimal kenaikan biaya adalah bahwa batas maksimal kenaikan adalah 39,92 persen. Apabila melebihi batas tersebut, maka NPV akan mengalami titik impas atau sama dengan Rp. 0;. Bahan baku merupakan bahan utama dalam pengolahan kerupuk cumi. Dalam usaha pengolahan kerupuk cumi, batas tertinggi kenaikan harga jual kerupuk cumi sebesar 39,92 persen dengan harga jual sebesar Rp. 
$65.000 ; /$ kg. Pada penurunan hasil penjualan batas minimumnya adalah sebesar 21,87 persn maka usaha tersebut tidak menguntungkan atau tidak layak untuk dijalankan.

Peningkatan harga baku dan penurunan harga jual pada batas tertentu untuk pengolahan usaha kerupuk cumi ini akan menyebabkan lamanya dalam pengembalian investasinya, serta faktor pemasaran produk yang tidak terlalu luas dan banyaknya pesaing usaha sejenis. Hal ini sesuai dengan penelitian yang dilakukan oleh Ngo dkk. (2019) yang menyatakan bahwa kenaikan biaya merupakan faktor yang memberikan pengaruh cukup besar terhadap kelayakan usaha pada hasil pengolahan produk perikanan. Faktor selanjutnya yang memberikan pengaruh cukup besar terhadap pengolahan hasil produk perikanan adalah penurunan hasil produksi.

\section{KESIMPULAN}

Berdasarkan tujuan dan hasil pembahasan pada penelitian ini maka dapat disimpulkan bahwa analisis kelayakan usaha kerupuk cumi berdasarkan 4 kriteria investasi yang digunakan pada usaha pengolahan kerupuk cumi di Desa weru Kecamatan Paciran Kabupaten Lamongan layak untuk dilanjutkan.

Analisis sensitifitas pada usahan pengolahan kerupuk cumi didapatkan hasil bahwa penurunan harga jual akan lebih sensitive apabila dibandingkan dengan penurunan harga bahan baku, untuk kenaikan harga bahan baku tertinggi akan dapat hasil sebesar 39,92 persen dan penurunan harga jual kerupuk cumi mempunyai batas terendah sebesar 21,87 persen.

\section{UCAPAN TERIMAKASIH}

Penelitian ini dapat dilaksanakanan dengan baik berkat bantuan dari berbagai pihak, untuk itu peneliti mengucapkan terimakasih kepada Lembaga Penelitian dan Pengabdian Masyarakat Universitas Islam Lamongan yang telah mendanai dan memfasilitasi kegiatan penelitian ini. Terimakasih pula kami haturkan kepada Dewan Redaksi Jurnal AGROMIX yang telah mereview dan memberikan masukan sebelum artikel dipublikasikan.

\section{DAFTAR PUSTAKA}

Amelia , R., Sumardianto, \& Suharto, S. (2020). Karakteristik kerupuk cum-cumi (Loligo, Sp.) dengan beda suhu oven pengering dan ketebalan kerupuk. Pena Akuatika, 19(1), 45-57. http://dx.doi.org/10.31941/penaakuatika. v19i1.1067

BPS. (2018). Inflasi dan Indeks Harga Konsumen. Badan Pusat Statistik.

Gitinjer, P. (1986). Analisis ekonomi proyek-proyek pertanian. Universitas Indonesia Press.

Hopkins, M. (2016). The case for project Net Present Value (NPV) and NPV risk models. PM Worls Journal, 5(6), 1-10.

Hutajulu, J., Kusumo, T., Saputra, A., Mualim, R., Handri, M., Sugriwa, E., ... \& Syamsuddin, S. (2019). Financial analysis in the exploitation of blue swimming crab Portunus pelagicus in Banten Bay, West Java, Indonesia. Aquaculture, Aquarium, Conservation \& Legislation, 12(2), 724-734.

Intyas, C. A., \& Firdaus, M. (2020). Analisis nilai tambah usaha kerupuk ikan cumi di desa Weru Kecamatan Paciran, Kabupaten Lamongan. Journal of Fisheries and Marine Research, 4(2), $214-221$. http://dx.doi.org/10.21776/ub.jfmr.2020.004.02.5

Irianto, H. E., \& Giyatmi, S. (2009). Teknologi Pengolahan Hasil Perikanan. Jakarta: Penerbit Universitas Terbuka.

Jumiati, D, R., \& Sudianto. (2019). Pengaruh penggunaan ekstrak kunyit (Curcuma domestica) terhadap mutu kerupuk cumi (Loligo sp.). Jurnal Ilmiah Perikanan dan Kelautan, 11(1), 55. http://dx.doi.org/10.20473/jipk.v11i1.11914

Nazir, M. (2005). Metode Penelitian. Bogor: Ghalia Indonesia.

Ngo, T., Hung, V., Ho, H., Thuy, T., Dao, \& Ngunyen, H. T. (2019). Performance of fish farms in vietnam, does financial access help improve their cost efficiency. International Journal of Financial Studies, 7(45), 1-10. https://doi.org/10.3390/ijfs7030045

Principal , E. A., Saputra , S. W., \& Purwati, F. (2019, May). Technical crab (Portunus pelagicus) fishing business in Rembang District, Indonesia. Russian Journal of Agricultural and Socio-Economic Sciences, 5(89), 18-26. https://doi.org/10.18551/rjoas.2019-05.03

Searles, K. I., Muchhausen, S. V., Kirwan, J., Chiswell , H., Maye, D., Prosperi, P., . . Tsakalou. (2018, June). Adding value to the fish, business strategies in fish farming and small-scale fishery. AIEAA Conference-Evidence-based policies to face new challenges for agri-food systems,. http://dx.doi.org/10.22004/ag.econ.275654

Shava, E., \& Gunhidzirai, C. (2017). Fish farming as an innovative strategy for promoting food security in drought risk regions of Zimbabwe. Jàmbá: Journal of Disaster Risk Studies, 9(1), 1-10. https://doi.org/10.4102/jamba.v9i1491

Tama, B. M., Gumilar, I., Rochima, E., \& Nurhayati, A. (2019, March). Salted fish processing financial business analysis of (Sardinella Fimbriata Valenciennes) in Muara Angke, North Jakarta. Global Scientific Journals, 7(3), 1-10.

Winarti, L., Herlina, S., \& Permadi, R. (2018). Analisis kelayakan dan model pengembangan usaha kerupuk ikan dengan pendekatan enterprenuerial marketing. Jurnal Agribest, 2(2), 92-106. https://doi.org/10.32528/agribest.v2i2.1622 